\title{
LPG LEAKAGE ALARM SYSTEM USING VARIOUS CIRCUITS
}

\author{
A. Vedanthsrivatson \\ UG Scholar \\ Department Of Electronics And Communication Engineering \\ SRM TRP Engineering College Trichy, India
}

\begin{abstract}
The principle target of this section is to advise about the gas spillage and to control the gas spillage in a legitimate way. With the expanded expense of fuel, the majority of them favor employing gas vehicles rather than petroleum/diesel vehicles. Utilizing gas in vehicles is exceptionally a dangerous issue, which will cause significant mishaps because of the spillage of LPG Gas. To modify this issue, LPG gas spillage is ensured by utilizing an insurance framework. We planned and grew such sort of framework to forestall the number of mishaps in gas vehicles.
\end{abstract}

Keywords: LPG Gas, risk issue, protection system, etc.

\section{INTRODUCTION}

The present industry is dynamically moving towards computerization. Two standard portions of the current mechanical computerizations are programmable controllers and robots. To help the tedious work and to serve humanity, today, there is a general penchant for developing an intelligent movement.

The "LPG LEAKAGE ALARM" is arranged and made to accomplish the various endeavors in an adversarial atmosphere of industry. The astute machine is stacked with a couple of units, for instance, the LPG GAS sensor, Relay, and driver circuit and alarm, which all the while working with the help of a start of-the-workmanship microcontroller. This firefighter structure is to the specific progress. This model system can be applied feasibly and successfully in an all.

\section{Brief methodology:}

The productive condition makes the people utilize the gas vehicles. In our LPG gas spillage protection structure, we will have

$\begin{array}{ll}\text { - } & \text { LPG gas sensor, } \\ \text { - } & \text { Amplifiers, } \\ \text { - } & \text { Alarm, } \\ & \text { Comparator and }\end{array}$

\section{- A hand-off}

The LPG gas sensor is fixed near the gas chamber. Suppose there are any gas spills, the sensor resources, and grants the relating electrical caution sign to enhancer circuit. The enhancer circuit achieves extra escalation of signs.

Such a system is used to hinder the disasters that happened on account of spillage of gas in gas vehicles, similarly as homes. It is a safer structure to use to evade any disasters.

\section{EXISTING SYSTEM}

- It can't be remote monitoring and control of the battery system.

- It can't be changing the connections of the battery using Relay.

- It can't be used reliably for industrial and domestic needs.

- Low power consumption can't be control by control systems.

\section{BLOCK DIAGRAM}

\section{BLOCK DIAGRAM DESCRIPTION}

\section{A.GAS SENSOR}

Electrochemical gas sensors are gas detectors that measure the concentration of a target gas by oxidizing or reducing the target gas at an electrode and measuring the resulting current.

\section{Construction}

The sensors contain a couple of anodes, on occasion four, in contact with an electrolyte. The cathodes are normally produced by fixing a high surface region significant metal on to the porous hydrophobic layer. The cathodes and housing are normally in a plastic housing, which contains a gas area opening for the gas and electrical contacts. 


\section{International Journal of Engineering Applied Sciences and Technology, 2020 \\ Vol. 5, Issue 8, ISSN No. 2455-2143, Pages 269-272 \\ Published Online December 2020 in IJEAST (http://www.ijeast.com)}

\section{Hypothesis of activity}

The gas diffuses to penetrable layer to the working anode where it is oxidized or lessened. This electrochemical reaction achieves an electric stream that experiences the external circuit.

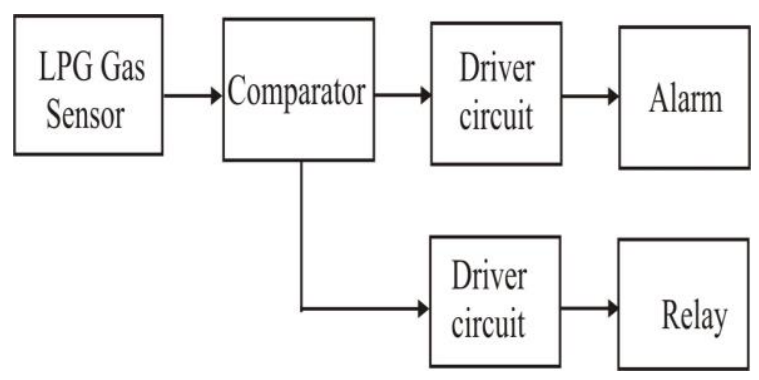

At the counter anode, the same and reverse reaction occurs, with the ultimate objective that if the working terminal is oxidation, by then the counter cathode is an abatement.

\section{A. COMPARATOR}

A standard activity amp working in an open hover plan (without negative analysis) can be used as a comparator. Right when the non-disturbing data $(\mathrm{V}+)$ is at a higher voltage than the adjusting input $(\mathrm{V}-)$, the high expansion of the activity amp makes it yield the best voltage it can. Right when the non-changing information $(\mathrm{V}+)$ plunges under the disturbing data (V-), the activity amp yields the most negative voltage it can. Since the yield voltage is limited by the reserved voltage, for an activity amp that uses a fair, split stock (filled by \pm VS), this action can be created:

\section{B. RELAY}

\section{Hand-off:}

An exchange is an electrically worked switch. Current flowing through the twist of the exchange makes an appealing field that pulls in a switch and changes the switch contacts. The twist current can be on or off, so moves have two switch positions, and they are twofold throw (changeover) switches.

Rate it very well, maybe as much as $100 \mathrm{~mA}$ for moves expected to work from lower voltages. Most ICs (chips).
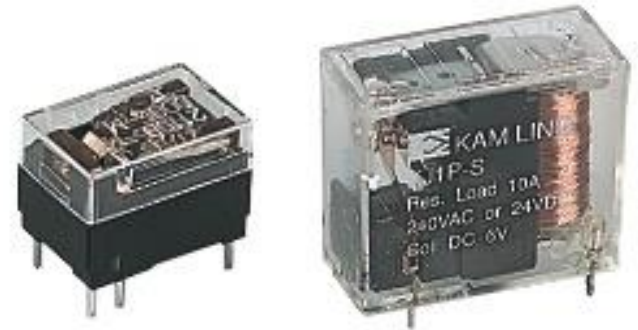

Moves are commonly SPDT or DPDT. In any case, they can have fundamentally more blueprints of switch contacts. For instance, moves with four strategies of changeover contacts are quickly accessible. Most trades are anticipated PCB mounting, yet you can weld wires unmistakably to the pins giving you require care to put forth an attempt not to smooth the plastic event of the hand-off.
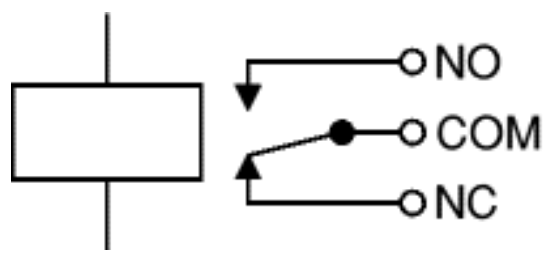

C. ALARM

A caution gives a perceptible or visual admonition about an issue or condition.

\section{Signal:}

A bell or beeper is a hailing contraption, regularly electronic, commonly used in vehicles, nuclear family machines, for instance, a microwave, or game shows. From the start, this contraption relied upon an electromechanical system, which was unclear from an electric ring without the metal gong (which makes the ringing uproar).

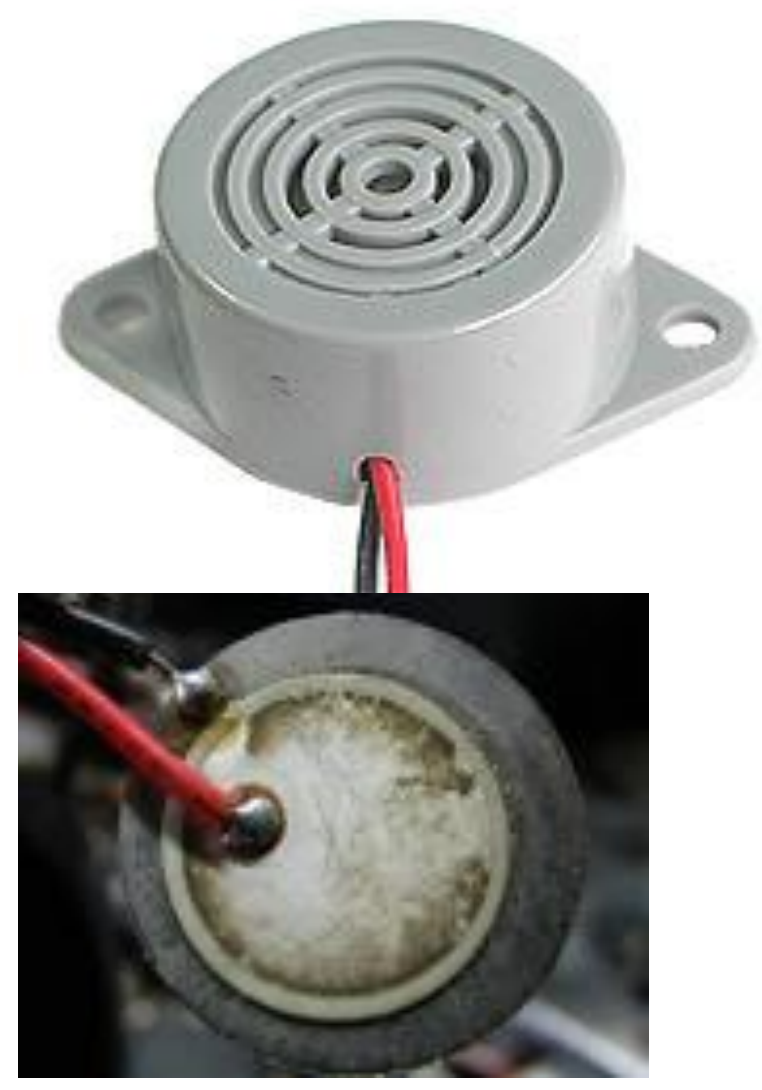




\section{International Journal of Engineering Applied Sciences and Technology, 2020 \\ Vol. 5, Issue 8, ISSN No. 2455-2143, Pages 269-272 \\ Published Online December 2020 in IJEAST (http://www.ijeast.com)}

\section{OVERALL CIRCUIT DIAGRAM DESCRIPTION}

\section{POWER SUPPLY}

\section{Block diagram}

The forced air system voltage, usually $220 \mathrm{~V}$ RMS, is related to a transformer, which steps that forced-air system voltage down to the level of the ideal dc yield. A diode rectifier by then gives a full-wave changed voltage that is from the outset filtered by a fundamental capacitor channel to make a dc voltage. This ensuing dc voltage usually has some wave or ac voltage assortment.

A regulator circuit kills the waves and besides remains as before dc regarding whether or not the data dc voltage vacillates or the pile related with the yield dc voltage changes. This voltage rule is typically obtained using one of the acclaimed voltage regulator IC units.

\section{Working guidelines:}

\section{Transformer}

The potential transformer will venture down the force supply voltage $(0-230 \mathrm{~V})$ to $(0-6 \mathrm{~V})$ level. At that point, the optional potential transformer will be associated with the accuracy rectifier, which is built with the assistance of an operation amp. The upsides of utilizing an exactness rectifier are it will give top voltage yield as DC, rest of the circuits will give just RMS yield.

\section{Extension rectifier}

Exactly when four diodes are related, as showed up in the figure, the circuit is called an augmentation rectifier. The commitment to the circuit is applied to the cockeyed opposite corners of the association, and the yield is taken from the abundance of two corners.

The best voltage that appears across the pile resistor is anyway never outperforming $500 \mathrm{v} 01$ ts, as an eventual outcome of the little voltage drop across the diode. In the augmentation rectifier showed up in view $\mathrm{B}$, the best voltage that can be altered is the full helper voltage, which is 1000 volts. In like manner, the apex yield voltage across the store resistor is right around 1000 volts. With the two circuits using a comparable transformer, the framework rectifier circuit conveys a better return voltage than the customary full-wave rectifier circuit.

\section{IC voltage controllers}

Voltage regulators incorporate a class of commonly used ICs. Regulator IC units contain the equipment for reference source, comparator intensifier, control device, and over-trouble security, all in a single IC. IC units give the rule of either a fixed positive voltage, a fixed negative voltage, or an adaptable set voltage. The regulators can be picked for action with load streams from numerous mill amperes to a few amperes, identifying with control evaluations from mill watts to a few watts.

POWER SUPPLY $(+5 \mathrm{~V},+12 \mathrm{~V})$
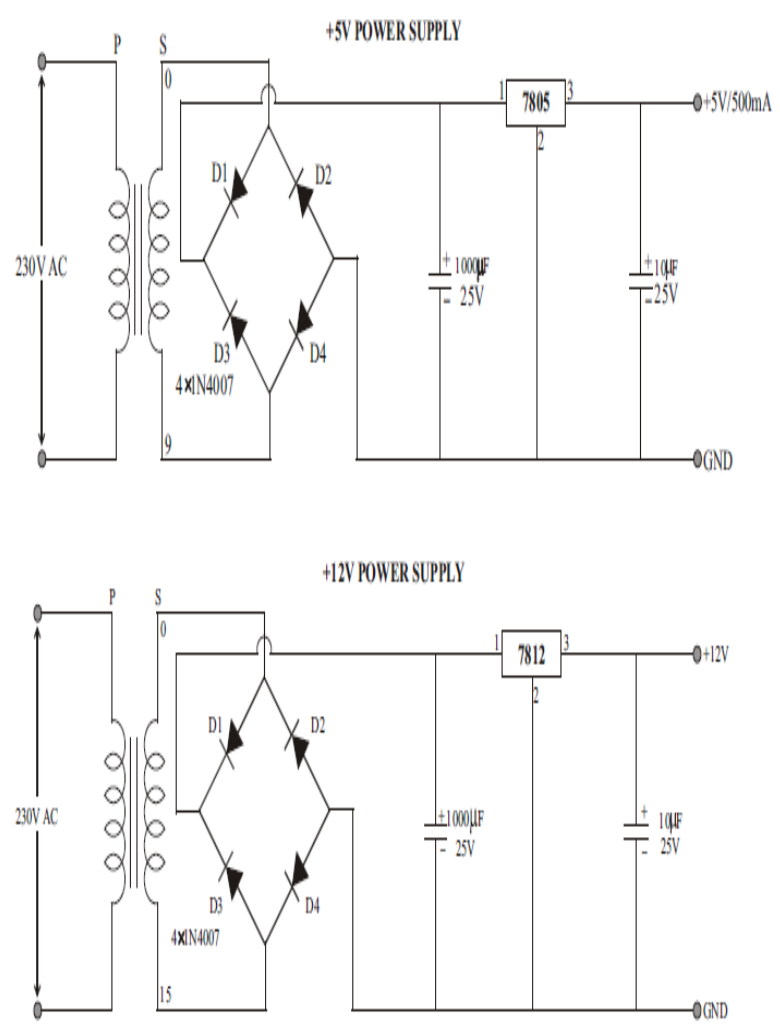

\section{CONCLUSION}

The advancement in science and innovation is a relentless cycle. New things and new innovations are being concocted. As the innovation develops step by step, we can envision the future in which thing we may involve each place. The proposed framework dependent on simple gadgets is discovered to be more reduced, easy to use, and less unpredictable, which can promptly be utilized to perform. A few dull and dreary undertakings. Despite the fact that it is planned to remember about the requirement for industry, it can reach out for different purposes, for example, business and examination applications. Because of the likelihood of high innovation utilized, this" LPG gas discovery and alert" is a controlled equipment control circuit completely. The element that makes this framework is the base for future frameworks. The rule of the advancement of science is that "nothing is unimaginable." So we will anticipate a splendid and complex world. 


\section{International Journal of Engineering Applied Sciences and Technology, 2020 \\ Vol. 5, Issue 8, ISSN No. 2455-2143, Pages 269-272 \\ Published Online December 2020 in IJEAST (http://www.ijeast.com)}

\section{REFERENCES}

1. Schreiber, J. W. (2018). U.S. Patent No. 10,125,780. Washington, DC: U.S. Patent and Trademark Office.

2. Gray, G. L. (2019). U.S. Patent No. 10,379,166. Washington, DC: U.S. Patent and Trademark Office.

3. Gopal, C. S. S. K., Prabu, A. V., Kumar, G. S., Krishna, P. G., \& Student, P. G. (2017): UPS parameter monitoring and controlling using IoT and GSM. International Journal of Pure and Applied Mathematics, 116(6), 133-139.

4. Hsieh, H. M., Chien, H. C., \& Peng, Y. H. (2018). U.S. Patent No. 10,097,034. Washington, DC: U.S. Patent and Trademark Office.

5. Brookshire, K., Spitaels, J. S., Deokar, V. M., \& Rodenhiser, F. W. (2017). U.S. Patent No. 9,595,742. Washington, DC: U.S. Patent and Trademark Office.

6. Cohen, D. C., \& Melanson, M. R. (2017). U.S. Patent No. 9,774,205. Washington, DC: U.S. Patent and Trademark Office.
7. Cheng, W. S., \& Hwang, Y. (2019). U.S. Patent Application No. 16/175,772.

8. Drummond, J. P., \& Lynam, N. R. (2002). U.S. Patent No. 6,396,408. Washington, DC: U.S. Patent and Trademark Office.

9. Kutluay, K., Cadirci, Y., Ozkazanc, Y. S., \& Cadirci, I. (2005): A new online state-of-charge estimation and monitoring system for sealed lead-acid batteries in telecommunication power supplies. IEEE Transactions on Industrial Electronics, 52(5), 13151327.

10. Sachdev, K., Negi, N., Kumar, S., Lakhanpal, A., \& Singh, D. (2008). U.S. Patent Application No. 11/892,526.

11. Wei, Y., Hsueh, K. F., \& Jang, G. W. (1994): Monitoring the chemical polymerization of aniline by open-circuit-potential Polymer, 35(16), 3572-3575.

12. Trimberger, S. M., \& Lesea, A. H. (2010). U.S. Patent No. 7,831,873. Washington, DC: U.S. Patent and Trademark Office. 